\title{
Phylogenetic placement of Itajahya: An unusual Jacaranda fungal associate
}

\author{
Seonju Marincowitz ${ }^{2}$, Martin P.A. Coetzee ${ }^{1,2}$, P. Markus Wilken ${ }^{1,2}$, Brenda D. Wingfield ${ }^{1,2}$, and Michael J. Wingfield ${ }^{2}$
}

${ }^{1}$ Department of Genetics, Forestry and Agricultural Biotechnology Institute (FABI), University of Pretoria, P.O. Box X20, Pretoria, 0028, South Africa

${ }^{2}$ Forestry and Agricultural Biotechnology Institute (FABI), University of Pretoria, P.O. Box X20, Pretoria, 0028, South Africa; corresponding author e-mail: seonju.marincowitz@fabi.up.ac.za

\begin{abstract}
Itajahya is a member of Phallales (Agaricomycetes), which, based on the presence of a calyptra and DNA sequence data for $I$. rosea, has recently been raised to generic status from a subgenus of Phallus. The type species of the genus, $I$. galericulata, is commonly known as the Jacaranda stinkhorn in Pretoria, South Africa, which is the only area where the fungus is known outside the Americas. The common name is derived from its association with the South American originating Jacaranda mimosifolia trees in the city. The aim of this study was to consider the unusual occurrence of the fungus in South Africa, to place it on the available Phallales phylogeny and to test whether it merits generic status. Fresh basidiomes were collected during the summer of 2015 and sequenced. Phylogenetic analyses were based on sequence data for the nuc-LSU-rDNA (LSU) and ATPase subunit 6 (ATP6) regions. The results showed that $I$. rosea and $I$. galericulata are phylogenetically related. They are also clearly distinguished from other members of Phallales such as Phallus spp. and Dictyophora spp., and so our new data supports the raising of Itajahya to the generic level.
\end{abstract}

\author{
Key words: \\ Homobasidiomycetes \\ molecular phylogeny \\ Phallomycetidae \\ phalloid fungi \\ South Africa \\ stinkhorns
}

Article info: Submitted: 15 May 2015; Accepted: 30 July 2015; Published: 5 August 2015.

\section{INTRODUCTION}

The generic name Itajahya was introduced by Möller (1895) for a fungus discovered near the city of Blumenau in Santa Catarina state, Brazil. The peculiar name derives from that of the river Itajahy in that region. The fungus is an unusual and poorly known member of Phallales, and its taxonomic position has been debated purely on the basis of morphological features. The fungus resides in Phallaceae, a family encompassing members of the order with unbranched basidiomata. The family Phallaceae is distinguished from the only other family recognized in the order, Clathraceae (Chevallier 1826) in which the genera have branched basidiomata and are known as "lattice stinkhorns". Recent developments in the taxonomy of the order based on DNA sequence data can be found in Hosaka et al. (2006) and Trierveiler-Pereira et al. (2014). Itajahya now includes four species, with I. galericulata as type species, and has, until recently, been treated as a subgenus of Phallus (Malençon 1984, Kreisel 1996).

Cabral et al. (2012) considered the taxonomic placement of Phallus roseus, a species treated by Malençon (1984) and Kreisel (1996) in Itajahya, as a subgenus of Phallus. Cabral et al. (2012) were able to collect fresh specimens of $P$. roseus in the Rio Grande do Norte of Brazil, and for the first time generated DNA sequence data for this poorly-known fungus. Their phylogenetic inference showed that $P$. roseus did not cluster with Phallus species, and they raised Itajahya to generic rank.

The decision of Cabral et al. (2012) to treat $P$. roseus in Itajahya was based on the fungus having a calyptra at the apex of its receptacle and the molecular datasets. A calyptra is also present in the type of the genus, I. galericulata. However, there was no sequence data then available for $I$. galericulata or the other two species of Itajahya: I. hornseyi described from Australia (Hansford 1954) and I. argentina from Argentina (Spegazzini 1898, 1927). The placement of $P$. roseus in Itajahya rested solely on morphological evidence. This could be contested given the poor understanding of the taxonomic value of morphological features in Phallales. For example, the data of Cabral et al. (2012) confirm earliest suggestions that the conspicuous indusium in Dictyophora is apparently not phylogenetically informative.

Itajahya galericulata was first described from southern Brazil where it is known from three states: Santa Catarina (Blumenau), Rio de Janeiro, and Rio Grande do Sul (Pelotas) (Möller 1895, Lloyd 1907). The fungus has also been recorded in Bolivia (Fries 1909). Long \& Stouffer (1943) reconsidered a fungus initially identified as Phallus impudicus collected during a field study in 1941 in arid regions of New Mexico and Arizona noting a resemblance to I. galericulata, but they considered it "improbable that a tropical wet climate plant could grow under such arid conditions". However, their careful morphological characterization of specimens

\section{@ 2015 International Mycological Association}

You are free to share - to copy, distribute and transmit the work, under the following conditions:

Attribution: $\quad$ You must attribute the work in the manner specified by the author or licensor (but not in any way that suggests that they endorse you or your use of the work)

Non-commercial: $\quad$ You may not use this work for commercial purposes.

No derivative works: You may not alter, transform, or build upon this work.

For any reuse or distribution, you must make clear to others the license terms of this work, which can be found at http://creativecommons.org/licenses/by-nc-nd/3.0/legalcode. Any of the above conditions can be waived if you get permission from the copyright holder. Nothing in this license impairs or restricts the author's moral rights. 
Table 1. Itajahya galericulata samples collected during this study in the Pretoria area of South Africa with GenBank accession numbers.

\begin{tabular}{lllcc}
\hline Isolate no. & Culture collection no. & Herbarium no. & \multicolumn{2}{c}{ GenBank accession no. } \\
\cline { 3 - 5 } & & & nucLSU & ATP6 \\
\hline \hline Sample 1 & CMW 44299 $=$ CBS 140330 & PREM 61268 & KR071850 & KR071847 \\
Sample 2 & CMW 44300 = CBS 140331 & PREM 61269 & KR071851 & KR071848 \\
Sample 3 & CMW 44301 = CBS 140332 & PREM 61270 & KR071852 & KR071849 \\
\hline
\end{tabular}

${ }^{a}$ Culture collection of the Forestry and Agricultural Biotechnology Institute (CMW), University of Pretoria, South Africa.

${ }^{b}$ CBS-KNAW Fungal Biodiversity Centre (CBS), Utrecht, The Netherlands.

${ }^{\mathrm{C}}$ National collection of Fungi in South Africa (PREM), Roodeplaat, Pretoria, South Africa.

from Arizona and New Mexico led them to conclude that they were dealing with $I$. galericulata. Although they considered this possibility, they were unable to justify establishing a new species for the fungus based on the morphological characteristics.

Intriguingly, there is only one locality outside the Americas where I. galericulata is known: the city of Pretoria, South Africa. Here the fungus commonly occurs in association with Jacaranda mimosifolia, a tree that is abundantly planted as an ornamental in gardens and for lining streets. Indeed, Pretoria is commonly referred to as the "Jacaranda city" from the very large number of trees that cover it in a blanket of purple flowers in the Southern Hemisphere spring. While the occurrence of $I$. galericulata in Pretoria is unusual, it is perhaps more interesting that the fungus, known locally as the "jacaranda stinkhorn" (van der Westhuizen \& Eicker 1994) occurs in a very close association with $\mathrm{J}$. mimosifolia, a tree native in the area of Brazil and Bolivia where the fungus was first discovered. This suggests that $I$. galericulata was probably introduced into South Africa with these trees. Based on herbarium records, I. galericulata was first collected and recognized in Pretoria, South Africa, by Ethel M. Doidge on 21 January 1915.

During the summer of 2015 , we were able to collect a number of fresh specimens of $I$. galericulata in Pretoria. This provided an opportunity to obtain DNA sequence data for this unusual genus of Phallales of which the taxonomy has been confused. The overall aim was to place the fungus in the available phylogeny of Phallales, to test the hypothesis of Cabral et al. (2012) that Itajahya deserves generic status, and to consider the unusual occurrence of this poorly know fungus in South Africa.

\section{MATERIALS AND METHODS}

\section{Collection of samples}

Three basidiomes of Itajahya galericulata were collected in the Brooklyn and Hatfield residential areas of Pretoria in January 2015 (Table 1, Fig. 1). These typically appear in dry sandy soils after summer rainfall and they were consistently associated with the root systems of Jacaranda mimosifolia trees. Dried basidiomes and cultures were deposited in the National Collection of Fungi in South Africa (PREM), Roodeplaat, Pretoria, South Africa, and living cultures were deposited in the culture collection (CMW) of the Forestry and Agricultural Biotechnology Institute, University of Pretoria,
Pretoria, South Africa and in the CBS-KNAW Fungal Biodiversity Centre (CBS), Utrecht, The Netherlands.

\section{DNA extraction, PCR and sequencing}

Fragments of three basidiomes were used for DNA extraction following the protocol used by Cabral et al. (2012). The DNA was quantified on a NanoDrop spectrophotometer (NanoDrop Technologies, Wilmington, DE), before the nuc-LSUrDNA (LSU) and ATPase subunit 6 (ATP6) gene regions were amplified using the LROR/LR5 (Vilgalys \& Hester 1990) and ATP61/ATP62 (Kretzer \& Bruns 1999) primer sets, respectively. Each gene region was amplified using the KAPA Taq PCR Kit (Kapa Biosystems, Cape Town) according to the appropriate protocols from Cabral et al. (2012). All successful PCR products were purified using the Zymo Research DNA Clean \& Concentrator kit (Zymo Research Corporation, Irvine, CA).

Purified fragments were cloned into Escherichia coli using the pGem-T Easy Vector cloning kit (Promega, Madison, WI) following the manufacturers' instructions. Cloned inserts were amplified directly from colonies using a colony $\mathrm{PCR}$ reaction (Sambrook \& Russell 2001). Amplification was achieved using the FastStart High Fidelity PCR System (Roche Diagnostics, Mannheim) with the SP6 (Butler \& Chamberlin 1982) and T7 (Dunn et al. 1983) primer set. Each sample was purified using the Zymo Research DNA Clean \& Concentrator kit and sequenced in both directions using the vector specific primers, the BigDye Terminator v. 3.1 Cycle Sequencing Kit (Applied Biosystems, Foster City, CA) and an ABI PRISM 3100 Genetic Analyzer (Perkin Elmer, Warrington). Resultant electropherograms were imported into the CLC Main Workbench package (CLC Bio, Aarhus), trimmed for vector-specific and low quality sequence and subsequently assembled. One ATP6 and one LSU sequence from each basidiome was selected for phylogenetic analysis.

\section{Phylogenetic analyses of sequence data}

ATP6 and LSU datasets generated in this study incorporated sequences from the basidiomes collected in Pretoria as well as sequences obtained from GenBank for species included in the study of Cabral et al. (2012) (Tables 1-2). Multiple sequence alignments were made using the online version of MAFFT (Katoh \& Standley 2013) with alignment strategy set to Auto. Character congruency between the ATP6 and LSU datasets was determined using the partition homogeneity test (PHT) implemented in PAUP (Swofford 2002) after excluding missing, ambiguously aligned and uninformative 

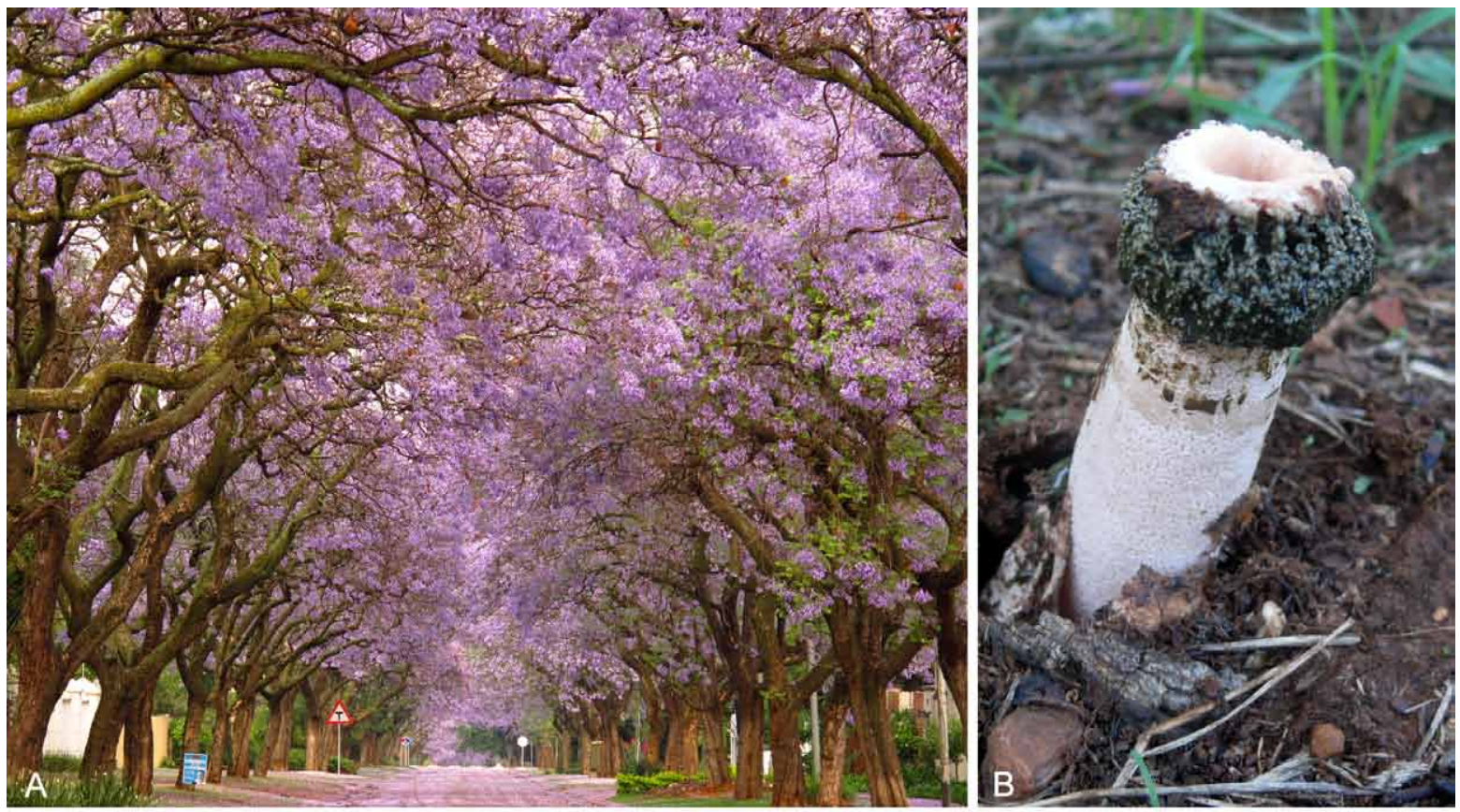

$\frac{D}{7}$
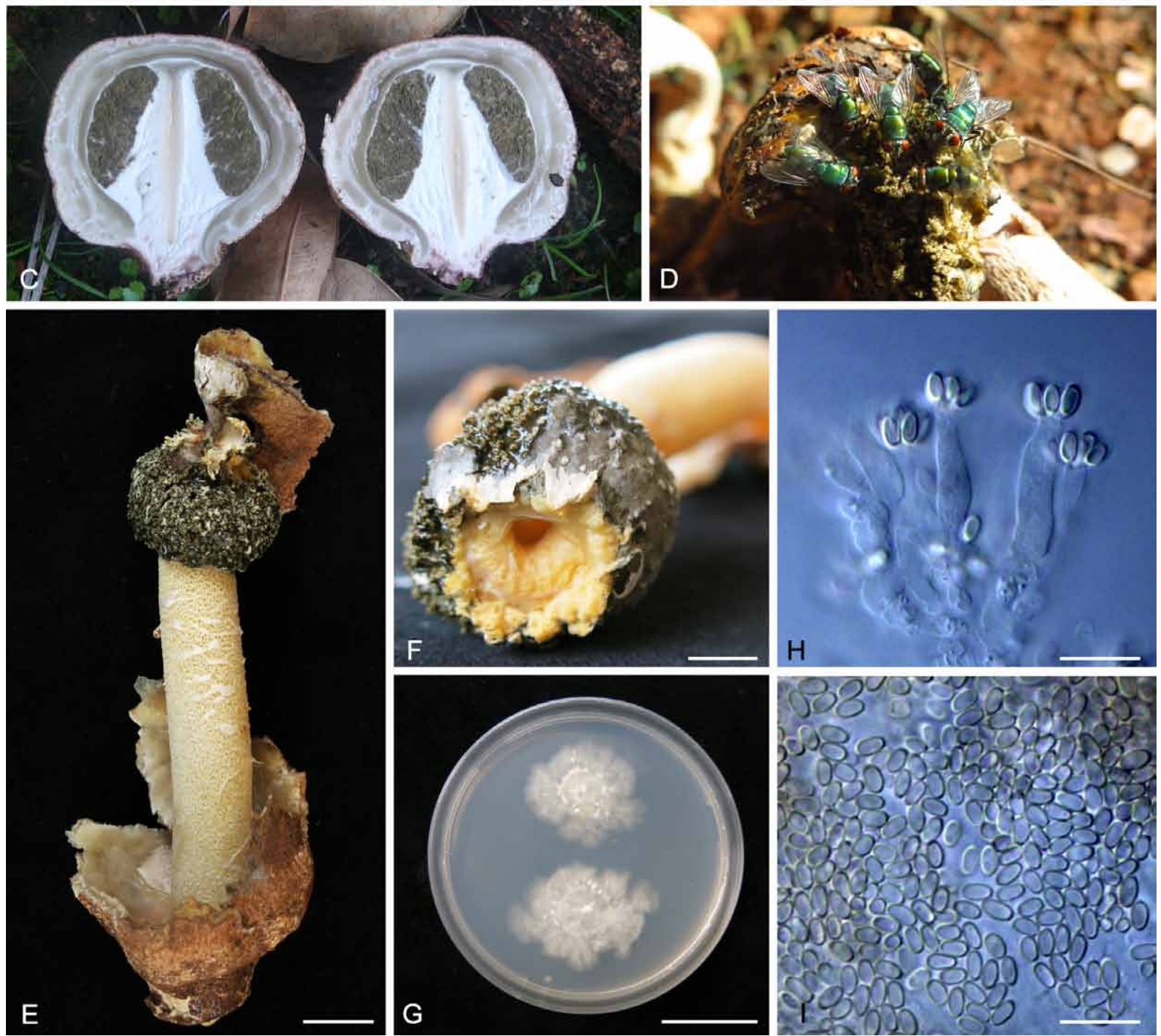

Fig. 1. Habitat and features of Itajahya galericulata in Pretoria, South Africa. A. Jacaranda mimosifolia trees flowering in Brooklyn, Pretoria. B. Basidiome emerged from the ground (PREM 61269). C. "Egg" dissected to show inner features. D. Flies attracted by putrid odour produced by the fungus. E. Basidiome emerged in a moist chamber in the laboratory (PREM 61268). F. Close-up of the apex of basidiome showing calyptra and gleba (PREM 61270). G. Colonies grown for 3 months on $2 \%$ Yeast-malt extract agar (CMW $44300=$ CBS 140331). H. Basidia. I. Basidiospores. Bars: $\mathrm{E}=1.5 \mathrm{~cm}, \mathrm{~F}=1 \mathrm{~cm}, \mathrm{G}=2 \mathrm{~cm}, \mathrm{H}-\mathrm{I}=10 \mu \mathrm{m}$. 
Table 2. GenBank accession numbers of taxa used for phylogenetic analyses.

\begin{tabular}{|c|c|c|}
\hline \multirow[t]{2}{*}{ Species } & \multicolumn{2}{|c|}{ GenBank accession no. } \\
\hline & nucLSU & ATP6 \\
\hline Anthurus archeri & DQ218624 & DQ218913 \\
\hline Abrachium floriforme & JF968440 & JF968438 \\
\hline Aseroe rubra & DQ218625 & DQ218914 \\
\hline Clathrus chrysomycelinus & DQ218626 & DQ218915 \\
\hline Dictyophora duplicata & DQ218481 & DQ218765 \\
\hline Dictyophora indusiata & DQ218627 & DQ218917 \\
\hline Dictyophora multicolor & DQ218628 & DQ218918 \\
\hline Gelopellis sp. 1 & DQ218630 & DQ218919 \\
\hline Gelopellis sp. 2 & DQ218631 & DQ218920 \\
\hline Ileodictyon cibarium & DQ218633 & DQ218922 \\
\hline Ileodictyon gracile & DQ218636 & DQ218925 \\
\hline Itajahya rosea & JF968441 & JF968439 \\
\hline Kobayasia nipponica & DQ218638 & DQ218926 \\
\hline Laternea triscapa & DQ218640 & DQ218928 \\
\hline Lysurus borealis & DQ218641 & DQ218929 \\
\hline Lysurus mokusin & DQ218507 & DQ218791 \\
\hline Mutinus elegans & AY574643 & AY574785 \\
\hline Phallobata alba & DQ218642 & DQ218930 \\
\hline Phallus costatus & DQ218513 & DQ218797 \\
\hline Phallus hadriani & DQ218514 & DQ218798 \\
\hline Phallus ravenelii & DQ218515 & DQ218799 \\
\hline Protubera borealis & DQ218516 & DQ218800 \\
\hline Protubera canescens & DQ218645 & DQ218932 \\
\hline Protubera jamaicensis & DQ218647 & DQ218933 \\
\hline Protubera maracuja & DQ218518 & DQ218802 \\
\hline Protubera parvispora & DQ218648 & DQ218934 \\
\hline Protubera sabulonensis & DQ218649 & DQ218935 \\
\hline Simblum sphaerocephalum & DQ218521 & DQ218806 \\
\hline Trappea darkeri & DQ218651 & DQ218938 \\
\hline
\end{tabular}

characters. This test showed that the datasets were congruent $(P=0.85)$, therefore aligned datasets were concatenated for downstream phylogenetic analyses.

Phylogenetic trees were obtained based on parsimony and Bayesian inference with Trappea darkeri as the outgroup species. Cladograms based on the combined datasets were generated in PAUP. Missing, ambiguously aligned and uninformative characters were excluded prior to the parsimony analysis. The most parsimonious trees were determined using a heuristic algorithm with random addition of sequences (10 replicates) and tree-bisection reconnection branch swapping (TBR). The same settings were used for bootstrap analysis, but with the addition of sequences set to "simple", and 1000 replicates.

Nucleotide substitution models that best fit the individual datasets were determined with jModelTest (Darriba et al. 2012) with models selected based on the Akaike Information
Criterion (AIC). The selected substitution models were applied to the individual gene partitions (LSU: TIM2+I+G and ATP6: TPM2uf $+1+G$ ) in the combined dataset for the Bayesian analysis. Phylogenetic trees were generated with $\mathrm{Mr}$ Bayes (Huelsenbeck \& Ronquist 2002) with the number of generations set to 4 million and using four Markov chain runs. The first $25 \%$ trees with low likelihood were discarded from each run after which the remaining trees from the individual runs were combined to obtain a consensus tree and posterior probability (PP) values. Effective sample size (ESS), as a measure of convergence, was analyzed in Tracer (http://tree. bio.ed.ac.uk/software/tracer/).

\section{RESULTS}

\section{Phylogenetic analyses of sequence data}

Using previously described primers, sequences for both the LSU and ATP6 regions were successfully amplified from all three basidiomes. The final LSU and ATP6 datasets included 691 and 667 characters, respectively. Of these, 135 characters were parsimony informative in the LSU dataset, while 214 characters in the ATP6 dataset were informative. In total 271 characters were included in the parsimony analysis after excluding missing, ambiguously aligned, and parsimony uninformative characters.

Parsimony analyses yielded four most parsimonious trees with a tree length of 908 steps. The consistency and retention index values were 0.476 and 0.729 , respectively. The topology of the consensus tree generated from Bayesian inference was congruent with the trees generated using parsimony. All nodes were supported with posterior probability (PP) values $>0.95$, with the exception of the node shared by Dictyophora indusiata and Phallus hadriani (Fig. 2). Phylogenetic trees generated from the parsimony and Bayesian analyses placed the sequences from Pretoria in a strongly supported clade (bootstrap support $=100 \%$, PP $<0.95)$. This clade formed a sister group to Itajahya rosea with high bootstrap support (96\%) and posterior probability (PP < 0.95). Trees generated in this study placed sequences from species of the genera Dictyophora and Phallus in a monophyletic group supported by their posterior probability values (PP < 1), but somewhat marginal bootstrap value of $70 \%$. This group was placed sister to $I$. rosea and the samples from Pretoria with PP $=1$, but with low bootstrap support $(64 \%)$.

\section{DISCUSSION}

This study provided DNA sequence data for a poorly-known yet taxonomically important member of Phallales. The data for two gene regions have shown clearly that Itajahya galericulata groups separately from species of Phallus and Dictyophora. They also support the results of Cabral et al. (2012) who raised Itajahya to generic status to accommodate Phallus roseus, which they transferred to Itajahya. Their placement in Itajahya was based on morphological features and sequence data of $I$. rosea, but not of the type species, I. galericulata. Our results confirm that $I$. rosea is 


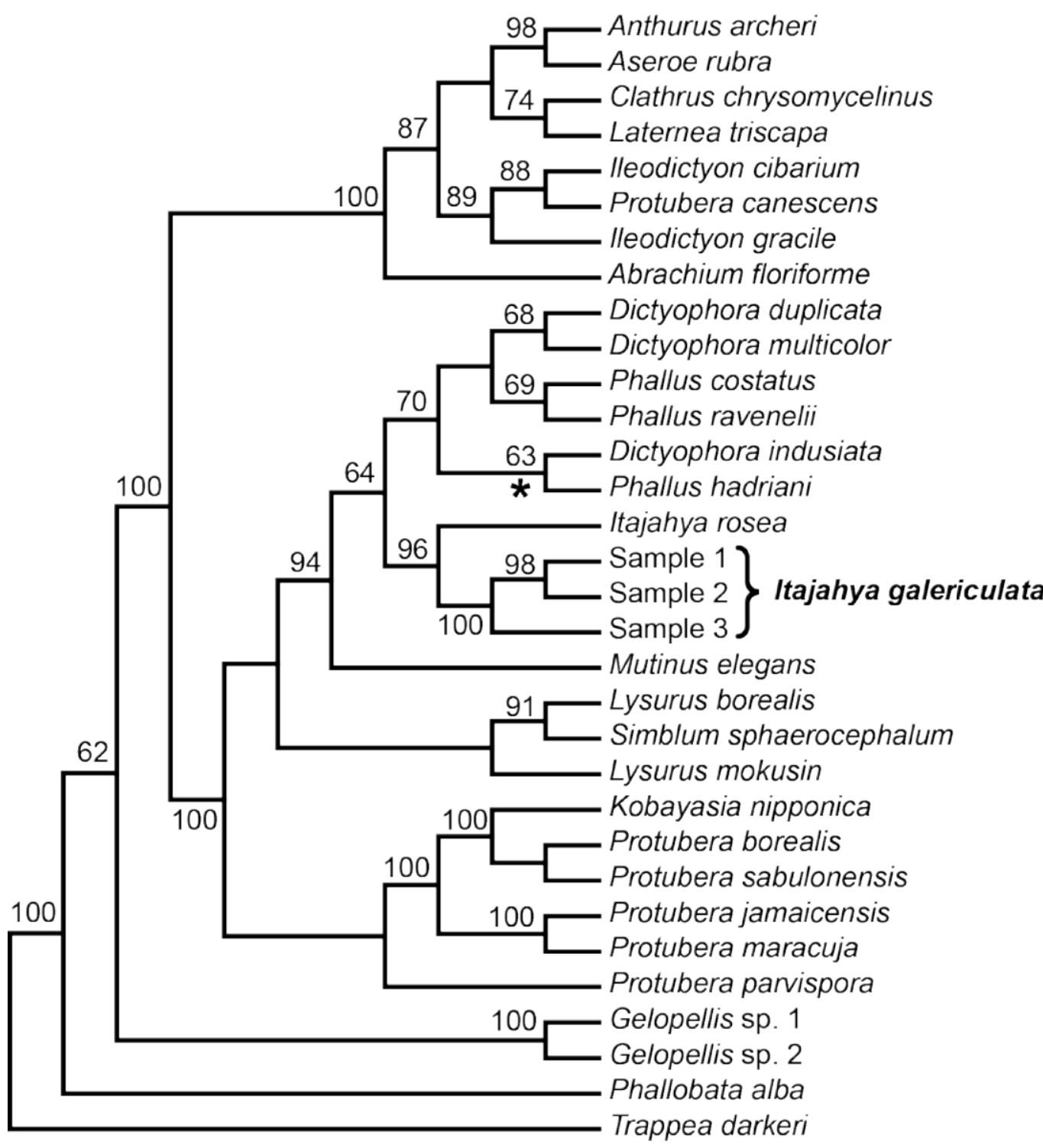

Fig. 2. Cladogram based on parsimony and generated from combined nuclear LSU and ATP6 DNA sequence for Itajahya galericulata and other member species of Phallales. Bootstrap values greater than $60 \%$ are indicated on the tree branches. All nodes, except that indicated with an asterisk, have posterior probability values greater than 0.95 .

phylogenetically related to the type species, I. galericulata, and the two species can be comfortably accommodated in the same genus.

There is relatively little information available on the biology of Itajahya species. As it was first discovered in tropical Brazil, the subsequent discovery of $I$. galericulata in dry sandy environments of New Mexico and Arizona was unexpected (Long \& Stouffer 1943). This habitat contrasted with most Phallales, which occur on rich organic substrates in moist situations. Itajahya galericulata is found in Brazil either in clay banks of forest streams or among roots of dead trees where the soil is rich in decaying leaves (Möller 1895). In contrast, in South Africa it is typically found in dry sandy soil, although it occurs annually after rain and is possibly associated with litter of $\mathrm{J}$. mimosifolia. Similarly, the Australian I. hornseyi is also reported from a sandy soil habitat (Hansford 1954). We consider that this genus of Phallales, unlike most other species in the order, has species adapted to tolerate in relatively dry conditions, although we acknowledge that there are some exceptions in Phallus; for example, in the UK $P$. hadriani characteristically occurs in sand dunes associated with marram grass (Ammophila arenaria) (Watling \& Rotheroe 1989, Pegler et al. 1995) .

The occurrence of $I$. galericulata in South Africa and particularly its association with $\mathrm{J}$. mimosifolia trees is intriguing. That these trees originate in the area where the fungus was first described suggests the fungus was introduced into South Africa with these trees. The very close association between J. mimosifolia trees and its apparent absence from other environments in South Africa raises the question as to whether there might be a mutualistic relationship between them. The members of Phallaceae are, however, not known as mycorrhizal associates of trees, although Phallus hadriani could perhaps be mycorrhizal with Ammophila when in sand dunes (Hawksworth, pers. comm.). The form of the relationship between $J$. mimosifolia and $I$. galericulata remains unknown and requires further investigation for a better understanding of the dynamic ecology of the fungus. 
If $I$. galericulata was, as we believe is the case, introduced into South Africa with J. mimosifolia, the trees would probably have had to be introduced as potted plants as opposed to seeds, though we cannot exclude the possibility that the fungus could be seed-borne. The legal global movement of rooted plants is very difficult under contemporary quarantine regulations, which seek to prevent the concomitant introduction of alien and potentially invasive organisms. At the time of the first discovery in South Africa in 1915, such care would not have been required. Although there is no evidence to suggest that $I$. galericulata is invasive, its establishment in South Africa illustrates the potential dangers associated with the global movement of living plants for planting out (Andjic et al. 2011).

We have no doubt that the fungus that we have treated as I. galericulata from South Africa is the same species as that described from Brazil. It would, however, be useful to compare specimens from these two areas phylogenetically; this would ideally require the collection of fresh specimens from Brazil. For the present, the DNA sequences for this species from South Africa provide a foundation for inclusion of the genus in phylogenetic studies of Phallales.

We hope this study will stimulate further interest in Itajahya and encourage mycologists to collect additional specimens from which DNA can be extracted and used in phylogenetic analyses. It would, for example, be particularly interesting to compare sequence data from specimens collected in New Mexico and Arizona with ones from South Africa and Brazil. Long \& Stouffer (1943) considered whether their collections might represent a species different to I. galericulata, but they were unable to make a distinction based on morphology; DNA comparisons would enable us to assess whether the geographical separation had led to any genotypic differences between the populations.

\section{ACKNOWLEDGEMENTS}

We thank Martin Kemler for translating Möller's 1895 paper, Mario Saparrat for providing Spegazzini's papers, and Riana Jacobs for assisting with Itajahya galericulata specimens in the National Collection of Fungi in South Africa (PREM).

\section{REFERENCES}

Andjic V, Dell B, Barber P, Hardy G, Wingfield MJ, et al. (2011) Plants for planting; indirect evidence for the movement of a serious forest pathogen, Teratosphaeria destructans, in Asia. European Journal of Plant Pathology 131: 49-58.

Butler ET, Chamberlin MJ (1982) Bacteriophage SP6-specific RNA polymerase. I. Isolation and characterization of the enzyme. Journal of Biological Chemistry 257: 5772-5778.

Cabral TS, Marinho P, Goto BT, Baseia IG (2012) Abrachium, a new genus in the Clathraceae, and Itajahya reassessed. Mycotaxon 119: 419-429.

Chevallier FF (1826) Flore Générale des Environs de Paris. Vol. 1. Paris: Ferra.

Darriba D, Taboada GL, Doallo R, Posada D (2012) jModelTest 2: more models, new heuristics and parallel computing. Nature Methods 9: 772.
Dunn JJ, Studier FW, Gottesman M (1983) Complete nucleotide sequence of bacteriophage T7 DNA and the locations of T7 genetic elements. Journal of Molecular Biology 166: 477-535.

Fries RE (1909) Über einige Gasteromyceten aus Bolivia und Argentinien. Arkiv för Botanik 8(11): 1-34.

Hansford CG (1954) Australian fungi. II. New records and revisions. Proceedings of the Linnean Society of New South Wales 79: 97-141.

Hosaka K, Bates ST, Beever RE, Castellano MA, Colgan III W, et al. (2006) Molecular phylogenetics of the gomphoid-phalloid fungi with an establishment of the new subclass Phallomycetidae and two new orders. Mycologia 98: 949-959.

Huelsenbeck JP, Ronquist F (2001) MRBAYES: Bayesian inference of phylogeny. Bioinformatics 17: 754-755.

Katoh K, Standley DM (2013) MAFFT Multiple sequence alignment software version 7 : improvements in performance and usability. Molecular Biology and Evolution 30: 772-780.

Kretzer AM, Bruns TD (1999) Use of atp6 in fungal phylogenetics: an example from the Boletales. Molecular Phylogenetics and Evolution 13: 483-492.

Kreisel H (1996) A preliminary survey of the genus Phallus sensu lato. Czech Mycology 48: 273-281.

Lloyd CG (1907) Concerning the phalloids. Mycological Notes 26: 325-340.

Long WH, Stouffer DJ (1943) Studies in the Gasteromycetes-IX The genus, Itajahya in North America. Mycologia 35: 620-628.

Malençon G (1984) Phallus roseus A. Delile 1813, alias Itajahya rosea (Delile) Ed. Fischer 1929. Bulletin de la Société mycologique de France 100: 15-33.

Möller A (1895) Brasilische Pilzblumen: Botanische mittheilungen aus den Tropen. Part 7. Jena: Gustav Fischer.

Pegler DN, Laessœ T, Spooner BM (1995) British Puffballs, Earthstars and Stinkhorns: an account of the British gasteroid fungi. Kew: Royal Botanic Gardens.

Sambrook J, Russell DW (2001) Molecular Cloning: a laboratory manual. $3^{\text {rd }}$ edn. Cold Spring Harbor: Cold Spring Harbor Laboratory Press.

Spegazzini C (1898) Fungi Argentini novi v critici autore Carolo Spegazzini. Anales del Museo Nacional de Historia Natural Buenos Aires 6: 81-288.

Spegazzini C (1927) Gasteromicetas Argentinas. Physis Revista de la Sociedad Argentina de Ciencias Naturales 8: 421-435.

Swofford DL (2002) PAUP*: phylogenetic analysis using parsimony (*and other methods). Version 4. Sunderland, MA: Sinauer Associates.

Trierveiler-Pereira L, da Silveira RMB, Hosaka K (2014) Multigene phylogeny of the Phallales (Phallomycetidae, Agaricomycetes) focusing on some previously unrepresented genera. Mycologia 106: 904-911.

van der Westhuizen GCA, Eicker A (1994) Field Guide Mushrooms of Southern Africa. Cape Town: Struik.

Vilgalys R, Hester M (1990) Rapid genetic identification and mapping of enzymatically amplified ribosomal DNA from several Cryptococcus species. Journal of Bacteriology 172: 4238-4246.

Watling R, Rotheroe M (1989) Macrofungi of sand dunes. Proceedings of the Royal Society of Edinburgh 96B: 111-126. 